\title{
O DEBATE ENTRE CENTRALIZADORES E FEDERALISTAS NO SÉCULO XIX A trama dos conceitos
}

Ivo Coser

A análise do debate de ideias entre centralizadores e federalistas no Império tem sido objeto de diversos trabalhos no campo das ciências sociais (Carvalho, 1993, 2002; Nunes, 1999; Rego, 1989; Werneck Vianna, 1997). Esses trabalhos abordaram o debate a partir das obras de dois autores: Visconde do Uruguai e Tavares Bastos. ${ }^{1}$ As obras desses autores figuram como textos clássicos, não apenas acerca do debate político imperial, mas a partir de sua análise são formuladas chaves interpretativas mais amplas acerca do pensamento político brasileiro (Faoro, 1994; Santos, 1978; Werneck Vianna, 1997, 2000).

Uma chave de leitura para o pensamento político Imperial aponta que o liberalismo foi integrado num modelo mais amplo, que levou esta doutrina a cumprir o papel de uma ampliação da raison d'etat. As doutrinas liberais desempenharam

Artigo recebido em julho/2010

Aprovado em março/2011 um papel importante, fundamentando a investidura de novas elites no poder, fornecendo uma racionalidade modernizadora para a integração com as economias do Ocidente capitalista, para a ascensão do talento empresarial, bem como para a internalização de regras jurídicas. Sua mensagem, entretanto, não se expandiu a ponto de universalizar a mensagem do individualismo (Morse, 1988; Faoro, 1994; Santos, 1978). Numa determinada leitura, esse bloqueio foi construído em razão de um Estado patrimonial capaz de cooptar a sociedade e seus movimentos (Faoro, 1994). Os valores liberais teriam permanecidos presos ao modelo arquitetônico organicista das monarquias ibéricas (Morse, 1988, pp. 87-93). A sociedade ganha forma a partir da intervenção do soberano, seus indivíduos encontram espaço nessa configuração desenhada a partir de cima, estando-lhes negada a via de uma individualidade autodeterminada e conflituosa (Morse, 1988). Nessa chave de leitura, o pensamento cen- 
tralizador com sua ênfase na precedência do interesse público junto com a proeminência do poder central, como leitor privilegiado e ator único desse interesse, configura-se como um caso típico do iberismo (Morse, 1988, especialmente pp. 87-92). ${ }^{2} \mathrm{O}$ modelo americanista, proposto por Morse, encontraria no pensamento federalista e, em particular, em Tavares Bastos um americanismo adaptado ao contexto nacional.

Essa incapacidade do liberalismo em moldar o conteúdo do pensamento político brasileiro aponta para o papel dos instrumentos autoritários nesta reflexão; não sem razão Morse integra na sua interpretação a proposta de Wanderley Guilherme dos Santos (Idem, pp. 91-91). De acordo com essa interpretação, no pensamento liberal brasileiro manifesta-se um dilema: como não existe uma sociedade liberal, não pode haver instituições liberais; para a construção dessa sociedade torna-se necessário um sistema político autoritário (Santos, 1978, p. 93). Ambas as leituras apontam para o papel proeminente desses instrumentos não liberais na moldagem de seu conteúdo.

O presente artigo propõe uma abordagem distinta. Com relação às interpretações acerca do debate entre centralizadores e federalistas, consideramos dois aspectos. Em primeiro lugar, analisamos o debate .deslocando a ênfase sobre as obras clássicas para o debate realizado no parlamento e nos jornais durante a produção da legislação descentralizadora ao longo dos anos de 1820 e 1830 , e da sua revisão centralizadora efetuada entre 1837 e 1842 . Acreditamos que a análise do pensamento descentralizador brasileiro produzido em defesa do Ato Adicional (1834) não deva ficar restrita à reflexão de Tavares Bastos, escrita quase quarenta anos após a sua promulgação. ${ }^{3} \mathrm{Da}$ mesma maneira, consideramos que conhecer o pensamento centralizador brasileiro implica analisar uma obra importante como o Ensaio, porém levando em conta o debate produzido entre 1836 e 1842 . Os estudos, contudo, privilegiam unicamente o Ensaio, sem analisarem o debate travado no final da década de 1830 e começo da seguinte. Ao realizarem esse estudo, centrado nas décadas de 1830 e 1840, não revelam a singularidade desse livro, escrito ao final da década de 1850. O Ensaio deve ser pensado conjuntamente a dois aspectos: de um lado, discutir o livro em conjunto com as demais obras que, publicadas no mesmo período, compartilham das ideias do direito administrativo e, de outro, analisar a centralização como um instrumento fundamental da organização do Estado brasileiro ante os interesses existentes na sociedade e não apenas relativo ao tema do federalismo.

Identificamos nas obras clássicas o papel de sintetizar e revelar a natureza de uma concepção política (Brandão, 2007, p. 42), mas consideramos também que ideias centrais presentes nessas obras podem permanecer em segundo plano, enquanto não deslocamos esses trabalhos para um contexto mais amplo. A partir desses textos, podemos vislumbrar os conceitos políticos que os perpassam e que moldam seu conteúdo de maneira mais relevante do que a suposta captura da intenção do autor (Koselleck, 2002). Analisar a trajetória histórica dos conceitos nos permite repensar o papel do liberalismo no pensamento imperial.

Consideramos que esse pensamento molda decisivamente o conteúdo das três principais correntes: os liberais exaltados, os liberais moderados e os centralizadores. O projeto liberal moderado busca reformar o Estado de maneira a que o interesse das províncias e da sociedade desempenhe o papel de princípio organizador. O recuo dessa corrente diante do vasto contingente dos homens pobres livres implica modificar o ritmo das mudanças, mas mantém a precedência do interesse como mola do pacto entre as províncias. Os liberais exaltados, reconhecendo as diferenças entre as trajetórias do Brasil e do mundo liberal moderno, articulam o princípio da participação do cidadão na esfera municipal com a construção do Estado nacional. $\mathrm{O}$ pensamento centralizador reconhece o cidadão ativo como portador de direitos civis e interesses; estes, entretanto, somente ganham sua plenitude quando associados à expansão da capacidade regulatória do Estado. Tal incorporação implica alterar a dinâmica desses diretos e interesses, retirando-os da dinâmica individual e forçando-os a se ligarem a um projeto mais amplo. Centralizadores e federalistas operavam a partir de um modelo de Estado, o qual serve como parâmetro para o presente. Os valores do liberalismo - interesse, participação e 
direitos civis - apontam para um projeto de construção de Estado-nação que não estava inscrito no plano imediato da sociedade civil existente. Para essas correntes, a dominação patrimonial e a escravidão construídas ao longo do período colonial se, de um lado, são entendidas como um resultado natural da história, sobre a qual não se deve impor uma mudança brusca, de outro, é o passado a ser superado, tendo em vista um projeto de futuro da nação calcado no liberalismo moderno, por meio de um movimento lento no qual a forma política vai moldando o comportamento dos agentes sociais (Fernandes, 1975, pp. 37, 43, 53).

\section{De confederação a federação}

$\mathrm{Na}$ Constituinte de 1823 , o conceito de federalismo, ${ }^{4}$ seja para seus críticos, seja para seus defensores, envolvia a ideia de que as províncias poderiam sufragar ou não o pacto firmado na Assembleia Constituinte; após a assembleia nacional ter deliberado sobre as leis fundamentais, a soberania retornava às províncias. ${ }^{5}$ Ambos os grupos reconheciam a possibilidade da compatibilidade entre monarquia e federação. ${ }^{6}$ Ao grupo federalista interessava fundamentalmente assegurar a autonomia para as províncias, a forma de governo - monárquica ou republicana - seria apenas o meio para obter tal fato. $\mathrm{O}$ argumento federalista realizava uma análise das relaçôes das províncias para com o pacto constitucional partindo de uma ideia do direito natural, substituindo a figura do indivíduo no seu estado natural pelas províncias.

Que as províncias são ajuntamentos de homens com iguais direitos. Que neste exercício de direitos iguais e maneiras de maior utilidade se funda a união federal de homens, casas, vilas, cidades, províncias e reinos sujeitando-se todos ao Império de um, a quem tributão mantença e honra para salvação certa de todos, ajuntando-se os seus procuradores em concílio comum, para se estabelecerem as regras da prol da prosperidade geral, ficando a prol de cada casa à indagação mais perspicaz e interessada dos filhos (Ferreira França, sessão da Câmara dos Deputados de 18 de setembro de 1823, p. 130).

No argumento federalista, a província desempenharia o mesmo papel do indivíduo com relação à sua casa; o indivíduo tem interesse em buscar a prosperidade e a felicidade da sua casa. ${ }^{7}$ Nesse sentido, a província deve controlar as atividades que dizem respeito à realização dos seus interesses. $\mathrm{O}$ argumento federalista compreende a construção do bem público a partir da mesma lógica do cidadão e seus interesses no mercado; de cada indivíduo voltado para a consecução do seu interesse particular emerge a utilidade:

Cada cidadão é independente para tratar dos seus interesses, salvas as relaçôes que o unem com a sociedade. E porque não havemos de conceder a mesma independência aos municípios e províncias? Assim como cada um é independente para prover em seus interesses, sem oposição ao interesse geral, muitos reunidos devem ter a mesma independência circunscrita do mesmo modo e sempre subordinada à inspeção geral do governo, a quem compete vigiar sobre os interesses particulares, porque da sua soma resulta o interesse geral, que lhe toca promover (Vergueiro, sessão em 18 de setembro de 1823, p. 130).

Vergueiro representava a corrente política que até o começo da década de 1830 rechaçava a aplicação do federalismo pleno, no qual as províncias eram soberanas, ou seja, o modelo confederativo, em favor de um federalismo mitigado que conferisse autonomia sem que isso implicasse a perda ou a ameaça da unidade nacional. ${ }^{8}$

Seu argumento entendia a construção do Estado-nação como o resultado de uma agregação de interesses provinciais; cada unidade buscando a realização dos seus objetivos terminaria produzindo uma política nacional. O poder central velaria para que não houvesse conflitos armados, sem que isso significasse conduzir ou determinar os interesses das províncias. Essa formulação constitui-se numa peça-chave para entendermos o conflito entre centralizadores e federalistas. Quando juntamos 
as duas pontas do argumento federalista, isto é, o cidadão ativo gerindo a casa, as províncias e o aparelho público, podemos perceber que esse modelo visava a dar passagem ao interesse particular e provincial como a mola organizadora da sociedade. A herança portuguesa é vista como o elemento que bloqueia a passagem desse tipo de interesse. A reforma do Estado de maneira que ele seja montado a partir da província visava a esse objetivo político. Nesse momento, o tema da liberdade, a participação dos cidadãos ativos nos assuntos públicos e a descentralização a partir da província caminham juntos e formam um único polo em oposição ao pensamento centralizador. Tal acordo irá ruir a partir da radicalização da experiência regencial.

O conceito de federalismo ganha um sentido histórico e político distinto em razão do contexto e dos argumentos mobilizados em torno da defesa da Lei do Juiz de Paz (1827) e do Código do Processo (1832). A bibliografia sobre o tema refere-se às leis descentralizadoras, sem destacar a singularidade das ideias federalistas mobilizadas em torno do Juiz de Paz e do Código do Processo quando comparadas com o Ato Adicional. ${ }^{9}$ O recuo efetuado pelos liberais moderados nos anos de 1830 somente pode ser plenamente compreendido caso tenhamos em mente esta associação entre a ideia de federalismo e a experiência gerada a partir da Lei do Juiz de Paz e do Código do Processo. ${ }^{10}$

A chave de leitura para compreender o conteúdo do pensamento liberal nesse período encontra-se num enfoque que permite repensar o conceito de americanismo (Morse, 1988; Carvalho, 1998; Werneck Vianna, 1997; Werneck Vianna e Carvalho, 2000). Esse conceito enfatiza a reflexão que busca organizar a vida política e social a partir dos valores liberais do individualismo e do interesse de inspiração anglo-saxã. Sua leitura, no contexto brasileiro, destaca seu caráter de reforma, mas temerosa do encontro com o vasto contingente de homens pobres livres, e opta por um liberalismo de Estado, apostando no esclarecimento das elites (Werneck Vianna, 1997; Carvalho, 1993).

Consideramos que o conceito de americanismo, quando pensado para os liberais no período de 1827 até 1834 , requer uma inflexão; seus valores operam com a possibilidade de que o tema do interesse, chave na condução dos assuntos materiais, desempenhe um papel positivo nos assuntos políticos (Coser, 2008, cap. 2). Para esse aspecto, torna-se fundamental a ideia de um interesse bem compreendido. ${ }^{11}$ A abertura da máquina do Estado à participação poderia, por intermédio de um processo de aprendizagem, mobilizar o cidadão em direção ao bem comum. Para tanto, era fundamental mobilizar os cidadãos. Esse argumento foi construído sem que os liberais exaltados ignorassem a distância do contexto brasileiro em relação à experiência anglo-saxã. Sua reflexão é marcada pela compreensão da necessidade de adequar as instituiçôes ao meio social e histórico brasileiro e, ao mesmo tempo, pela ideia de disseminar o poder do Estado pelo país por meio dos mecanismos de participação do cidadão ativo, sem que esses movimentos sejam vistos como contraditórios, como estará presente na reflexão dos liberais moderados, na segunda metade da década de 1830 e, principalmente, dos conservadores. Essa articulação lhes confere um caráter único na reflexão política imperial.

A importância da eleição do juiz de paz a partir da promulgação do Código do Processo e as consequências políticas da participação do cidadão podem ser compreendidas pela análise de dois significativos jornais da época, O Astro de Minas e o Aurora Fluminense. ${ }^{12}$ Nesses jornais, podemos encontrar artigos exaltando os mecanismos de participação do cidadão nos assuntos da justiça a partir dos interesses presentes na sua esfera privada. O $A u$ rora Fluminense descrevia um eleitor apático situado na capital do Império voltado para a sua esfera privada (afeiçôes, relaçôes de comércio ou de família). ${ }^{13}$ Esse eleitor não ligava o seu destino às eleições do juiz de paz, persuadido que estava de que os assuntos públicos não iriam interferir na sua felicidade privada. Diversos conflitos desencadeados a partir da abdicação mostram-lhe que para proteger sua esfera privada era necessário participar dos assuntos relativos ao juiz de paz, interagir com outros cidadãos, mobilizar valores distintos daqueles presentes na esfera privada. ${ }^{14} \mathrm{O}$ Astro de Minas analisa com a mesma lógica um eleitor situado no mundo rural, no qual, lentamente, a partir das eleiçôes de juiz de paz, o cidadão iria cuidar dos assuntos públicos com o mesmo zelo utilizado em sua fazenda. ${ }^{15}$ 
Os articulistas projetam para a esfera estatal um exemplo retirado da esfera privada. $\mathrm{O}$ cidadão deve cuidar da máquina pública com o mesmo zelo com o qual vela pela sua posse privada. Para que esse sentimento se manifeste, é fundamental que os cidadãos da localidade cuidem da administração da Justiça. O interesse, nesse caso, desempenha um papel positivo, capaz de conduzir a máquina pública de acordo com regras que assegurem o direito dos cidadãos. No argumento federalista, o motor que move o cidadão e ergue o Estado nacional nasce na esfera privada sem referência a valores externos. A ideia de interesse bem compreendido formulada por Tocqueville nos permite compreender o conteúdo desse argumento (Tocqueville, 1977, livro I, cap. III). Quando observamos o pensamento federalista brasileiro formulado nesse momento, não estamos diante de uma obra de arte política, que combina elementos díspares, que pela engenhosidade destacaria a habilidade do ator, mas de um movimento simples, que se aferra aos interesses do cidadão ativo. Elementos como a capacidade do Estado em implementar ordens, aspecto que lhe conferiria força e unidade, não desempenham qualquer papel relevante nesse argumento. Por outro lado, este programa político de construção do Estado nacional a partir do interesse do cidadão nasce no município, a dimensão mais próxima do cidadão. O "patriotismo municipal", expressão de Tocqueville (apud Jasmin, 2000), aponta para a ideia de que essa esfera é o espaço institucional primordial para a manifestação do interesse bem compreendido. As figuras sobre as quais o cidadão deverá ter controle abarcam do topo da administração provincial (o presidente de província) até aquelas situadas no plano estritamente municipal (o delegado e o serventuário). Estamos, portanto, diante de um programa federalista que não está restrito ao reforço dos poderes provinciais - assembleia provincial -, mas que chega até o município, tomando-o como pedra de toque. O projeto federalista dos liberais exaltados busca construir o Estado nacional a partir dos interesses do cidadão ativo, sem que tal obra envolvesse uma dinâmica estranha ao cidadão.

Em diversos contextos políticos, ${ }^{16}$ os centralizadores atacavam o controle dos funcionários a partir da província ou do município, enfatizando a necessidade de que a ação do poder central vislumbrasse interesses estranhos aos da realidade local. Segundo esta corrente, a ideia federalista diminui a força do poder central, impedindo-o de atender a necessidade de "defesa do Império e da prosperidade geral". ${ }^{17}$ Para os centralizadores, é da natureza do arranjo federativo que os interesses provinciais busquem a sua satisfação sem atentar para um interesse que está para além da província.

É importante assinalar que os centralizadores apontam para dois problemas existentes no modelo federalista: o uso clânico do poder político permitido pelo arranjo federativo/confederativo e a precedência de que os interesses provinciais dispõem nesse modelo. Para os centralizadores, a construção do Estado-nação exige que esses interesses sejam superados em favor de uma política mais ampla. Usualmente, a bibliografia sobre pensamento centralizador destaca o seguinte aspecto: essa corrente manifestaria uma visão negativa acerca do controle exercido pelos chefes locais sobre os cargos políticos. Tal leitura ignora o movimento presente no argumento centralizador, qual seja, a necessidade de introduzir nas províncias valores estranhos à sua dinâmica natural.

\section{Ato Adicional}

A promulgação do Ato Adicional $(1834)^{18} \mathrm{e}$ o conteúdo de sua defesa assinalam modificações fundamentais no conceito de federalista. Em primeiro lugar, manifestava-se a percepção da inovação introduzida pela convenção de 1787 (Estados Unidos). Em segundo, o tema do interesse provincial ganhava relevância em detrimento do exercício da liberdade na esfera municipal, implicando uma reformulação do programa americanista, ganhando a sua feição de uma reforma pelo alto. E, em terceiro, o pacto entre as províncias é pensado como um espaço de competição.

Em maio de 1831, iniciava-se o debate do que mais tarde viria a ser conhecido como o Ato Adicional. Os federalistas enfatizam que a província possuiria negócios particulares, ${ }^{19}$ interesses particulares, ${ }^{20}$ bem particular; ${ }^{21}$ em todos os usos, estava presente a ideia de que a província possuía um conjun- 
to de assuntos distintos daqueles que eram comuns a todo o Império.

No aspecto relativo à distinção entre o conceito de confederação e o de federação, o caso norte-americano foi constantemente mencionado nos debates parlamentares. Os defensores do Ato Adicional chamavam a atenção para as alterações que estavam ocorrendo. Era um dado corrente que o Estado norte-americano teria sido formado a partir da reunião de estados independentes, porém, essa situação já não correspondia à realidade naquela ocasião. Naquele momento histórico, nos Estados Unidos, o poder central estava empenhado em uniformizar as leis, reforçando os laços comuns entre as partes, uniformizando as diversas leis estaduais. O poder central determinava os códigos nacionais, cabendo aos poderes estaduais adequar-se a esses limites previamente estabelecidos. ${ }^{22}$

Nessa perspectiva, a província molda seus interesses com base na mesma lógica que o indivíduo orienta sua ação no mercado. Observemos que no conceito de federação estava presente a ideia de um desenvolvimento desigual entre as províncias, e que tal consequência era inevitável. O mal de um desenvolvimento desigual era o preço a ser pago por um bem maior: o progresso advindo da competição.

Eu disse que as províncias devem ter toda a amplitude para se governarem; mas que era preciso que se afrouxassem o nó, e que ficassem sujeitas ao governo central por uma união doce e suportável; [...] Eu advoguei unicamente a causa da justiça com o objeto de impedir a separação. Eu não vejo, contudo, que já se tocou neste ponto, que ele traga consigo tão graves inconvenientes, nem que dê lugar a verificar-se um quadro tão triste como o que foi apresentado pelo Sr. Cunha, acontecer-lhe-ia o mesmo que sucede a respeito dos indivíduos, alguns dos quais são mais ricos e outros mais pobres. Haviam de florescer as províncias mais abundantes em produtos e ficar atrasadas aquelas que produzissem menos, as quais se verão por isso forçadas a limitar suas despesas, em proporção às suas rendas, até chegarem à maior prosperi- dade (Lino Coutinho, Sessão da Câmara dos Deputados de 17 de maio de 1831, p. 49).

O trecho citado se revela de fundamental importância. No argumento federalista, a rivalidade provincial possui aspectos positivos. É ela que estimula as províncias a buscarem o desenvolvimento, pois cada uma não deseja ser ultrapassada por outra. Se, de um lado, é da natureza da competição que ocorra uma distribuição desigual dos bens, de outro, tal distribuição estimularia a província menos desenvolvida a buscar os meios para atingir um padrão mais elevado de desenvolvimento. A montagem do interesse nacional ocorre a partir de uma competição entre as províncias. No argumento federalista, o bem geral, ou a justiça, que ao final iria estabelecer-se entre as províncias, seria fruto de uma ação de um agente (a província) voltada à consecução dos seus objetivos egoístas. Em nenhum momento, Lino Coutinho remete à busca da realização dos interesses provinciais, a alguma referência externa à província. Aquelas mais prósperas servem de modelo para as mais atrasadas. O Estado nacional é um espaço comum às diversas províncias, no qual cada uma busca maximizar sua situação dentro de limites que impeçam o conflito armado.

Dentro da corrente federalista, podemos encontrar divergências acerca do grau de atribuiçōes que deveriam ser dados às províncias, porém o elemento em comum que as une reside na precedência do interesse provincial na montagem do Estado-nação. E cada província é vista como o indivíduo movido pelos seus interesses. Dentro desse espaço, ocorre uma competição entre elas, e da racionalidade contida nessa competição emerge o motor do desenvolvimento. Ao centrarmos nossa análise na maneira pela qual os federalistas formulam a construção do interesse nacional a partir das províncias, não estamos postulando um "estatuto menor" para o argumento federalista. O projeto federalista explicitamente pensa o tema da construção do interesse nacional; ocorre que ele o faz a partir da dinâmica provincial. ${ }^{23}$

A ideia do interesse provincial como uma dimensão fundamental do conceito de federalismo emerge conjuntamente com a crítica ao funcionamento do Código do Processo. A corrente federalista rechaçava a possibilidade de que, a partir dos 
interesses do cidadão ativo situado no município, fosse possível construir o Estado-nação. Nos relatórios de ministro da Justiça de Limpo de Abreu e Alves Branco, ambos defensores do Ato Adicional e adversários da centralização, podemos encontrar a referência da eclosão de inúmeros conflitos armados provocados pelo Código do Processo (1834e 1836). Diante desse quadro, Limpo de Abreu e Alves Branco encaminharam propostas de reforma do Código do Processo.

O pensamento federalista procura deslocar a primazia política para o Legislativo provincial como um meio pelo qual seriam podados os excessos descentralizadores presentes no Código do Processo. Tendo por base os mecanismos presentes no Ato Adicional, os diversos legislativos provinciais iniciaram a reforma do Código do Processo (Coser, 2008, cap. 4). Os atos do Legislativo provincial atacavam as atribuiçóes dos cargos eleitos ou escolhidos a partir do município em favor do juiz de direito e dos prefeitos. O Ato Adicional realizava a mesma tarefa do regresso conservador, qual seja, o esvaziamento dos cargos eletivos em favor dos cargos nomeados, mas com uma diferença fundamental: quem realizava essa tarefa era o Legislativo provincial, tendo em conta os interesses provinciais e não os motivos do poder central. ${ }^{24}$

Estamos, portanto, perante uma inflexão decisiva no argumento federalista. Se, no contexto regencial, a corrente federalista pensou a construção do Estado nacional baseada no interesse bem compreendido, gestado no município, conciliando interesse e liberdade, a partir da segunda metade da década de 1830, essa formulação irá perder sua força. As elites provinciais situadas no Legislativo nacional e provincial conduzirão a reforma do Estado, de maneira que os interesses privados moldem seu conteúdo, sem que nessa tarefa sejam mobilizados os setores turbulentos ativos nas localidades, os quais ameaçavam cancelar o programa. Essa exclusão tornava o projeto americanista uma obra conduzida a partir do Estado. O conteúdo do projeto político dos liberais moderados, qual seja, tornar o interesse provincial a base do Estado nacional, permanece como um modelo que guia a ação no presente; entretanto, o ritmo das reformas deve ser freado de maneira a realizar seu conteúdo.

\section{$O$ conceito de centralização}

A Lei de Interpretação esvaziava a autonomia do Legislativo provincial em controlar os cargos mais importantes do Judiciário. Quando os defensores do Ato Adicional tomam a palavra para defendê-lo, emergem os temas do interesse provincial e da casa. ${ }^{25}$ Ao discutir o controle que o Legislativo provincial possui sobre a polícia judiciária, os federalistas mobilizam a ideia do domínio sobre a economia doméstica; o pacto federativo deveria ser o instrumento capaz de unir as diversas partes que compõem o Império brasileiro, permitindo a cada província manifestar livremente seus interesses sem referência a valores externos. A província deve encontrar, no pacto federativo, vantagens que lhe digam respeito exclusivamente. Dessa liberdade, podem emergir laços comuns, mas que brotam dela própria, e não da centralização que oprime. ${ }^{26}$

Segundo Teófilo Ottoni, de fato, os centralizadores têm razão em apontar a existência de leis provinciais absurdas. ${ }^{27} \mathrm{Em}$ Minas, porém, desde a promulgação do Ato Adicional, a administração da Justiça havia melhorado. O motivo pelo qual isso se dava residia no fato de Minas ser uma das províncias mais ilustradas. Um pouco mais adiante, o argumento de Ottoni indicava que o progressivo desenvolvimento da civilização no Brasil contribuiria para que cada vez um número menor de leis absurdas fosse promulgado. Estabelecendo essas premissas, Ottoni conclui que a supressão do Ato Adicional não poderia ser realizada, porque nas províncias mais civilizadas não eram encontrados motivos suficientes para cancelar a descentralização.

Em 1843, o ministro da Justiça escreve um relatório fundamental para a compreensão do pensamento centralizador. Logo na sua abertura é estabelecida uma contraposição essencial para compreender o pensamento centralizador: a vontade nacional e os interesses provinciais:

A linguagem ameaçadora e frenética dessa mensagem e afoiteza com que exigia de um dos Poderes Supremos do Estado, que destruísse atos nos quais acabava de concordar tão solenemente com uma imensa maioria das Câmaras legislativas, e que a vontade Nacional, legi- 
timamente representada, se curvasse diante do capricho de Representantes de interesses meramente provinciais, exorbitando das suas atribuições, e ostentando o seu caráter orgulhoso (Uruguai, Relatório de Ministro da Justiça de 1843, pp. 4-5).

O pensamento centralizador estabelecia uma contraposição entre vontade nacional e interesses meramente provinciais. Somente podemos entender essa contraposição caso tenhamos em mente a discussão estabelecida previamente acerca da ideia de interesse provincial conforme foi formulada entre 1831 e $1834 .{ }^{28}$ A adjetivação crítica - "meramente" faz referência à ideia defendida pelos federalistas de que a província deveria se mover tendo em vista seus negócios particulares, sem alusão ao todo. $\mathrm{Na}$ ótica dos centralizadores, essa ideia era incapaz de articular o Império brasileiro, fato que justificaria o sentido negativo de meramente. $\mathrm{O}$ argumento centralizador apontava para a necessidade de um poder central capaz de alterar os interesses provinciais, de guiá-los em direção a objetivos que não estariam presentes a partir da própria província. Nabuco de Araújo apontava para essa ideia em um discurso na câmara dos deputados: "essa tendência centralizadora me parecia necessária como um dique imposto à torrente dos desvarios das Assembleias provinciais;" (sessão da Câmara dos Deputados de 6 de abril de 1843 apud Uruguai, 1865, p. 45). O uso do termo vontade ${ }^{29}$ por Uruguai, bem como de dique por Nabuco de Araújo, é revelador dessa ideia de uma intencionalidade com vistas a um fim que de outra maneira não iria emergir. Nesse sentido, afastamo-nos da abordagem que restringe a polêmica entre centralizadores e federalistas a uma querela entre um grupo federalista, que assume explicitamente seus interesses regionais, e a corrente centralizadora, que, por meio de um subterfúgio, oculta seus interesses sob o manto da unidade nacional; ${ }^{30}$ a nosso ver, a questão central reside no conjunto de valores que essas correntes mobilizavam para pensar a ideia de interesse provincial.

O conceito de centralização envolve uma outra dimensão que diz respeito ao agente que leva a cabo as ações do poder central. Devemos compreender o passo seguinte do programa centralizador: a Refor- ma do Código do Processo. Segundo os centralizadores, é a partir da centralização que o Estado chama para si o exercício da justiça e dos seus agentes; centralizar significa ter controle exclusivo sobre os agentes encarregados de aplicar a justiça criminal. Ao mesmo tempo, o argumento centralizador enfatizou o tipo de funcionário que seria nomeado. Podemos recortar nessa corrente uma definição desse funcionário; sua natureza era distinta daquela do funcionário eleito. Aquele funcionário nomeado deveria possuir um conhecimento específico para o desempenho do seu cargo, deveria se dedicar exclusivamente às suas tarefas e para tanto deveria dispor de um salário e poderia ser deslocado pelo território nacional para não criar vínculos com a localidade, além de ser dotado de um salário e treinamento específico. Esse conteúdo foi confrontado com as características dos funcionários eleitos ou escolhidos na província - Juiz de Paz, Juiz Municipal e Promotor. ${ }^{31}$

As interpretações acerca do debate entre centralizadores e federalistas enfatizam um aspecto do argumento centralizador: o poder central seria um poder mais distante dos conflitos locais e, portanto, um árbitro mais confiável. Esse traço está correto, entretanto é apenas parte do argumento. Os debates em torno da Reforma do Código do Processo apontam para um aspecto tão importante quanto aquele: o tipo de funcionário que deveria emergir a partir da substituição do funcionário amador eleito ou escolhido na província.

Segundo os centralizadores, os funcionários amadores eram incapazes de enfrentar réus que dispusessem de proteção; estes contratavam advogados, que, com o domínio da lei, derrotavam facilmente aqueles. ${ }^{32} \mathrm{O}$ funcionário assalariado possui vínculos mais fortes com o Estado em virtude da sua dependência, na medida em que sua única fonte de sustento provém do Estado. Ao mesmo tempo, o programa político dos centralizadores, expresso na Reforma do Código, sustentava a superioridade das normas escritas em face do conhecimento que os funcionários locais possuíam decorrente do fato de habitar a localidade. ${ }^{33}$ Alguns dos funcionários importantes - delegados e subdelegados - permaneciam, entretanto, presos à dinâmica local. ${ }^{34} \mathrm{Os}$ centralizadores reconheciam que eles eram tirados 
dentre os mesmos cidadãos que poderiam servir como juiz de paz. É fundamental assinalar que os centralizadores não atribuíam a essas figuras nenhuma qualidade decorrente do seu treinamento, salário ou vínculo, traços presentes na sua defesa do juiz de direito, promotor e chefe de polícia. $\mathrm{Na}$ nossa visão, revela-se o fato de que, no pensamento centralizador, esses funcionários não possuem as mesmas qualidades positivas que caracterizam os funcionários mencionados anteriormente. A ação do poder central nunca pode prescindir da colaboração obtida na localidade. Tal aspecto é um traço fundamental para compreender os limites da capacidade do Estado Imperial (Carvalho, 1980; Werneck Vianna, 1997, pp. 33-47).

Destacar este tipo de funcionário nos permite assinalar quais eram os adversários que deveriam ser combatidos. No argumento centralizador podemos recortar dois grupos que eram mencionados como obstáculos aos funcionários amadores: os homens pobres livres e os potentados. No Relatório de Ministro da Justiça de 1841, eram analisadas as grandes revoltas regenciais. ${ }^{35}$ Sua atenção voltava-se para a massa de homens mobilizados nos conflitos que irrompiam pelos sertôes. Homens que, nesses conflitos desencadeados pelas disputas políticas, praticavam "crimes alheios à política e contra a propriedade" 36 e o faziam porque não tinham o "amor à propriedade" que o trabalho e a posse conferem aos cidadãos.

$\mathrm{Na}$ descrição do ministro da Justiça, a ação desses homens não tinha nenhum caráter político, sendo uma manifestação do atraso no qual eles viviam. Esses "homens ferozes" 37 não possuíam propriedade e laços de interesse, eram os homens pobres livres. Sua ação adquiriu, diante dos olhos dos centralizadores, um sentido contrário aos valores da civilização. Sua entrada na arena da política, com os conflitos ocorridos durante a Regência, traz consigo os valores provenientes dos sertôes.

Analisando o argumento centralizador, contudo, podemos assinalar outro ator político diretamente envolvido nos conflitos regenciais: os grandes proprietários. Segundo os centralizadores, "os homens bons veem-se forçados, em defesa própria, a oprimir para não serem oprimidos; constituem-se pequenos centros de força, a que se aglomeram o maior número de facínoras" (Uruguai, Relatório de Ministro da Justiça, 1841, p. 19).

O termo homens bons designa uma parcela que dispõe de recursos materiais que lhe permitam ocupar uma posição social elevada na hierarquia social: os grandes proprietários. A ação desses homens bons é descrita não como um procedimento que depende das suas vontades, mas como parte necessária de um sistema que os leva a agir dessa forma. Os elementos desse sistema são, em primeiro lugar, a legislação descentralizadora, um fator proveniente da intervenção humana. Em segundo, um aspecto que diz respeito a processos sociais que fogem à intervenção humana, a dicotomia entre regiōes marcadas pela barbárie, a maior parte do país, e aquelas civilizadas. ${ }^{38}$ Nesse sertão bárbaro, encontram-se a dispersão populacional, a ausência da disciplina produzida pelo trabalho, a falta de uma educação formal, os partidos clânicos, a precariedade dos meios da Justiça em se fazer presente e uma massa de homens sem vínculos para com o mundo do interesse e facilmente mobilizados para participar de disputas eleitorais com finalidade de obtenção de empregos. Esses traços sociais, combinados com a legislação descentralizadora, forçam homens bons a oprimir para não serem oprimidos.

Ilmar Rohloff de Mattos, tomando como ponto de partida o mesmo trecho do relatório de ministro da Justiça elaborado por Uruguai, no qual este deplorava o envolvimento dos homens pobres livres nos conflitos regenciais, argumenta que os Saquaremas, após as revoltas regenciais, buscavam reordenar as distinções calcadas numa sociedade desigual (1994, pp. 133-134 e 154-155). Sem discordar inteiramente dessa hipótese, interpretamos o pensamento dos centralizadores de maneira distinta. Tendo por base o mesmo relatório, consideramos necessário segui-lo até o final, quando o ministro da Justiça deplora o comportamento dos grandes proprietários. Nesse sentido, para compreender integralmente a reflexão dessa corrente, é fundamental assinalar a crítica que eles fazem ao personagem principal da Casa: o grande proprietário rural. ${ }^{39}$

A possibilidade aberta pela legislação descentralizadora de que os cidadãos elegessem funcionários no Poder Judiciário gerou, segundo Uruguai, "pequenos potentados", 40 os quais controlam a 
justiça eletiva. Nesses locais, "não parece que a população desses lugares possa ser chamada de população de homens livres, e Cidadãos de um Império Constitucional, mas sim hum complexo de pequenos feudos onde há senhores e vassalos" ${ }^{41}$. Vassalo denota o homem que recebia do senhor honra e benefício, tendo a obrigação de prestar serviços. Estabelecia-se, portanto, um vínculo em razão do favor prestado. Observando a expressão que lhe serve de antítese, qual seja, "cidadão de um Império Constitucional”, podemos perceber que Uruguai desejava ressaltar no vassalo o seu aspecto de dependência pessoal para com o senhor, em oposição ao cidadão que vivia protegido pela lei. A palavra cidadão apontava para aquele que vive sob um conjunto de leis que lhe confere direitos e deveres, independentemente da vontade pessoal daquele que as aplica. Temos nessa ideia a temática dos direitos civis do cidadão. $\mathrm{O}$ outro termo, feudo, permite-nos mencionar a ideia de que os traços que caracterizam o Estado seriam "a concentração do poder, a unidade e a força", ao passo que a "qualidade essencial do elemento federal é o fracionamento do poder" ${ }^{42} \mathrm{~A}$ descentralização produziria feudos que impediriam a qualidade essencial do Estado moderno, a unidade. A junção dessas duas ideias é fundamental para que possamos compreender o argumento centralizador: o tema dos direitos civis é produzido pelo reforço da unidade do poder central. Em outras palavras, os centralizadores propunham silenciar os conflitos armados, reforçando o poder do Estado-nação, por meio do qual garantiriam os direitos civis dos cidadãos. Os direitos civis, nessa perspectiva, são pensados como um instrumento de pacificação do Império; a ênfase não recai na ideia do indivíduo portador de direitos universais, mas na capacidade do Estado em exercer seu poder e de garantir a ordem social.

Os debates em torno da Reforma do Código oferecem uma perspectiva fundamental para compreendermos a relação entre os centralizadores e os federalistas com o meio social, marcada pelo distanciamento e pela tentativa de superação da prática usual na condução da justiça (Fernandes, 1975, p. 50). Seus projetos são determinados pela tentativa de superar a absorção privada dos cargos públicos pela elite local. É fundamental assinalar o lugar de onde os centralizadores falam. ${ }^{43}$ Seu argumento não fala do lugar das classes subalternas e da ampliação dos seus direitos políticos. Sua descrição negativa da ação política dos homens bons deve-se ao fato de que sua avaliação procede de um ator político que pensa a relevância da construção de um Estado-nação numa dimensão que supera os interesses imediatos dos grupos sociais, sejam aqueles presentes no Legislativo provincial ou no município.

Nesse aspecto, a ideia de iberismo constitui-se num instrumento fundamental para que possamos compreender o pensamento centralizador. ${ }^{44}$ Deslocar o tema dos direitos civis da figura do indivíduo tomado isoladamente, traço crucial no liberalismo anglo-saxão, para pensá-la como parte de um instrumento da pacificação e da construção do Estado-nação demonstra que, no pensamento centralizador, o cidadão é considerado a partir de uma obra mais ampla. O modelo de construção do Estado-nação encontra-se na teoria liberal moderna, proveniente do liberalismo francês, que articula direitos civis e força do Estado. ${ }^{45} \mathrm{Na}$ nossa leitura, o pensamento saquarema não emerge como uma experiência refratária aos valores liberais, mas como uma incorporação desses valores numa matriz distinta do liberalismo anglo-saxão.

\section{A década de 1860 e as grandes obras}

No final dos anos de 1850 e começo da década seguinte, os conceitos de centralização e federalismo incorporam novos temas, sofrendo modificações relevantes quando comparados ao período anteriormente analisado. A década de 1850 assinala o fim das revoltas regenciais; ao mesmo tempo, o país passava por um período de realizaçóes materiais e estabilidade política. Nos debates parlamentares, os centralizadores passam a ser confrontados com a ideia de que a legislação produzida no contexto dos anos de 1830 e 1840 já não era mais adequada para esse novo momento histórico. ${ }^{46}$ Os centralizadores modificam seu argumento, reconhecem que podem ter ocorrido exageros, os ajustes podem acontecer pontualmente, mas a centralização deve permanecer como um princípio político perma- 
nente. Isso implicava fundamentar a centralização em outras bases, distintas daquelas presentes nos anos de 1830 e 1840 . Nesse período, serão escritas as principais obras em defesa da centralização e da descentralização.

Se, nos anos de 1830-1840, o argumento centralizador enfatizou a polarização entre vontade nacional e interesses meramente provinciais, o novo contexto político assiste à emergência da contraposição entre interesse público e interesses particulares. Esse tema emerge, principalmente, por meio do Direito Administrativo, o qual foi introduzido no debate político brasileiro no começo dos anos de 1860 (Cabral, 1859; Rego, 1860; Uruguai, 1997 [1862]; Ribas, 1866).

O motivo teórico pelo qual se justificava a introdução do Direito Administrativo era o seguinte: o Estado como portador do interesse geral não pode entrar em contato com o particular como outro particular; as regras jurídicas destinadas a dirimir os conflitos entre interesses e direitos particulares, nesse caso, revelam-se inadequadas. Para esses autores, o Judiciário e o Legislativo seriam ramos do Estado mais afeitos aos interesses e aos direitos particulares ${ }^{47}$ e o poder central, como órgão que comanda a administração seria, por sua vez, aquele que incorporaria o interesse público. A administração seria movida, conforme escreveu Vicente Rego, por outro princípio: "A administração, independente na sua marcha, e fundada no interesse público, fonte da razão governamental, é sempre senhora de fazer novos regulamentos, de revogar ou alterar os antigos" (Rego, 1860, Item 8). O Estado, como portador do interesse geral, pode vir a ferir legitimamente direitos e interesses particulares, sacrificando o bem particular ao bem público. Nesse sentido, torna-se necessário estabelecer o contencioso administrativo e a dualidade jurisdicional, reconhece-se que os direitos e os interesses não podem ficar à mercê do arbítrio estatal (Rego, 1860, item 8; Uruguai, 1997 [1862], p. 62; Ribas, 1866, p. 5). O argumento centralizador reconhece que os direitos individuais são utilizados segundo a lógica do homem na sua individualidade; entretanto a condução do interesse público e suas relações com o indivíduo obedecem a uma lógica distinta daquela, expressam a primazia do interesse maior.
Entretanto, quando se associa, o homem não renuncia às suas liberdades, aos seus direitos individuais; [...] reserva para a sua inteligência e faculdades, o direito de suas relações privadas... [...] Com efeito, é desde logo manifesto que a gerência das relações do cidadão com o Estado, daquelas em a lei deu predomínio ao interesse coletivo, em que colocou este debaixo da alçada e proteção do Direito Público ou Administrativo... (Pimenta Bueno, 1978 [1858], pp. 5 e 7$)$.

A maneira pela qual podemos compreender tal precedência está na definição de interesses e direitos dos particulares dada por esses autores e sua relação com o interesse público. No campo do direito administrativo, interesse significa algo que é útil ou resulta em vantagem ao individuo: "O interesse [...] é o que é útil [...] a vantagem que resulta para este ou aquele indivíduo [...]" (Uruguai, 1997 [1862], cap. XV, p. 62). A ideia de interesse emerge de maneira tal que as vantagens são usufruídas apenas pelo indivíduo em razão da sua capacidade de tirar vantagens da sua ação. É da natureza do interesse individual a tendência "ao estéril egoísmo" (Idem, p. 61). É importante que não consideremos o pensamento centralizador como portador de uma visão pré-moderna do interesse. O pensamento centralizador compartilha da ideia de que o interesse é a mola do desenvolvimento da civilização. Um dos motivos apontados para a eclosão dos conflitos armados dos anos de 1830-1840 era a precariedade do interesse, visto como um freio que conteria o indivíduo.

Por sua vez, o direito diz respeito àquilo que é inerente ao cidadão ou proprietário em virtude da lei. ${ }^{48}$ A maneira pela qual o pensamento centralizador apresentava a ideia de interesses e de direitos colocava a ênfase na figura do indivíduo tomado isoladamente. Para essa corrente política, nem o interesse nem o direito individuais, com a sua dinâmica voltada para o próprio indivíduo, produzem benefícios para a sociedade. É sua captura pelo poder central que os conduz em direção ao interesse público.

Segundo Joaquim Ribas, o Estado tem duas tarefas. Como primeira, compete-lhe defender a 
população das agressóes externas; a segunda seria "subordinar ao fim social todos os fins parciais das individualidades" (Ribas, 1866, p. 46). Conforme esse autor irá escrever em outro trecho, cabe ao "Estado promover os interesses gerais ou coletivos" (Idem, pp. 46-47). A necessidade do Estado em conduzir a precedência do interesse público sobre os interesses individuais não é entendida como um traço do atraso existente na sociedade brasileira. Ao contrário, é um traço de todas as sociedades civilizadas: "Há certos interesses gerais ou coletivos de tão grande importância, que as leis de todas as nações que possuem alguma civilização não podem deixar de reconhecer ou definir" (Idem, p. 5). ${ }^{49} \mathrm{O}$ pensamento centralizador parte de um modelo de Estado no qual o interesse particular deve ser capturado pelo poder central de maneira a considerar o interesse público. Não houve receio de que o interesse individual conduzisse o cidadão ao abandono da liberdade pública, tema relevante em Tocqueville. ${ }^{50}$ Sua preocupação reside no dano que o interesse individual alçado a princípio organizador do Estado venha a causar na unidade nacional e na sua projeção no plano externo. ${ }^{51}$

A chave de leitura que nos permite compreender o Ensaio consiste em articular a discussão dos anos de 1830-1840 com a nova temática surgida da discussão entre interesses privados e interesses públicos. Nesse sentido, o trecho fundamental do Ensaio, no qual esses dois planos estão articulados, vem a ser o seguinte: "Sem centralização como ligar o Sul e o Norte do Império, quando tantas dessemelhanças se dão nos climas, territórios, espírito, interesse, comércio, produtos e estado social" (Uruguai, 1997 [1862], p. 395). O pensamento centralizador parte da inexistência de uma unidade, seja no plano dos interesses particulares existentes na sociedade, seja entre as províncias. Sua polêmica para com o pensamento federalista esteve centrada na sua concepção de que os interesses provinciais, inclusive das províncias mais civilizadas, eram incapazes de conferir uma unidade a esse conjunto de regiōes heterogêneas e se desdobra na sua avaliação de que os interesses particulares não eram capazes de conferir unidade e legitimidade ao Estado.
Perante essa ampliação do princípio da centralização, o pensamento federalista amplia seu argumento. O modelo federalista será o instrumento mais apropriado para que os interesses privados fecundem e desenvolvam a sociedade brasileira. $\mathrm{O}$ federalista alagoano estabelecia que o progresso social dependeria da expansão do interesse individual. O pensamento centralizador não discordaria, em parte, dessa ideia, entretanto o pensamento de Tavares Bastos dá um passo que o argumento centralizador intencionalmente repudia. Segundo ele, o Estado não deve estar anteposto ao interesse individual; ao contrário, deve estar ligado ao interesse individual, pois é sua expansão que gera o progresso; caso isso não ocorra, o órgão público se transforma num "ente imaginário, abstrato e arbitrário frente aos indivíduos" (Bastos, 1937 [1870], parte 1, cap. I, p. 19). O diagnóstico de que nos anos de 1830-1840 as províncias foram sufocadas agora recebe uma formulação mais ampla: "os erros administrativos e econômicos que afligem o Império, não são exclusivamente filhos [...] de tal ou qual partido que há governado. Eles procedem todos de um princípio político: a onipotência do Estado" (Idem, Carta, I, p. 12). Na década de 1860, a maneira pela qual o Ato Adicional é avaliado sofre a influência dessa nova perspectiva. $\mathrm{O}$ Ato Adicional teria concedido maior liberdade às provincias superiores em civilização (Idem, p. 173) e também autorizou os interesses particulares a moldarem o Estado (Idem, p. 263).

\section{Conclusão}

O presente artigo buscou mostrar as principais mudanças no conteúdo dos conceitos de centralização e federalismo. A compreensão dessas alterações nos foi permitida por uma análise que mobilizou um material mais amplo do que as grandes obras sobre o tema. Dessa maneira, pudemos revelar uma complexidade maior no sentido político desses conceitos. Nesse percurso analisamos o papel central que ideias importantes da teoria liberal do século XIX tiveram nesse debate. Nas décadas de 1830 e 1840, o conceito de centralização foi pensado a partir de uma contraposição en- 
tre interesses meramente provinciais e vontade nacional. No argumento centralizador, está presente a ideia de pacificar o país por intermédio da ação do poder central, na qual os direitos civis, para serem garantidos, requerem o seu reforço. $\mathrm{Na}$ década de 1860 , o conceito de centralização foi ampliado englobando o tema da precedência do interesse público em face dos interesses particulares. Tal subordinação não nasce da compreensão de um atraso existente na sociedade, o qual caberia ao Estado corrigir por meio de instrumentos autoritários, mas de uma precedência necessária decorrente da legitimidade que esse órgão possui perante a sociedade e que o autoriza a interferir e a regular os comportamentos sociais. Essa legitimidade está vinculada a um modelo de Estado moderno proveniente da teoria liberal. O cidadão, seus direitos civis e interesses particulares devem ser conduzidos a seguir a dinâmica do interesse público formulado pelo poder central, de outra maneira serão apenas expressão do egoísmo individual. Inicialmente, o conceito de federalismo emerge associado à ideia de confederação. Posteriormente, os liberais exaltados formulam a descentralização como um veículo pelo qual a participação e a justiça se articulam positivamente. Os cidadãos, mediante o exercício da liberdade política, internalizam a lei e protegem sua esfera privada. Tal ato decorre do seu interesse individual, o qual, deslocado do seu egoísmo pela política, constrói a separação entre público e privado. A construção do Estado-nação seria feita sem a necessidade de mobilizar valores externos aos interesses do cidadão ativo, estando ausentes temas como a unidade do Estado nacional ou a sua projeção no plano externo. A mudança do conceito de confederação para federalismo implicou uma maior ênfase ao tema da competição pacífica entre os interesses das províncias. Ao mesmo tempo, a articulação virtuosa entre participação e justiça a partir do município foi substituída pelo tema da precedência do Legislativo provincial como intérprete desse interesse. $\mathrm{Na}$ década de 1860 , a esses temas foi acrescida a ideia de que o Estado Imperial teria sido refratário aos interesses individuais, cabendo ao modelo federalista sua reforma.

\section{Notas}

1 Paulino José Soares de Souza (Visconde do Uruguai) publicou seu principal trabalho, Ensaio sobre o direito administrativo, em 1861, enquanto Tavares Bastos publicou Cartas do solitário (1865) e A Província (1870).

2 Devemos assinalar as análises inovadoras desenvolvidas por Werneck Vianna e Carvalho (2000), acerca do pensamento saquarema a partir da interpretação proposta por Morse.

3 Usualmente os trabalhos tomam como a principal fundamentação do Ato Adicional (1834) os textos de Tavares Bastos (1861-1870), enquanto a defesa do regresso conservador (1837-1843) tem como base o Ensaio (1862)

4 A definição contemporânea de federalismo apresenta-o como um sistema de governo no qual o poder é dividido entre o governo central (a União) e os governos regionais. A experiência histórica que gera esse novo conteúdo é a construção do Estado norte-americano a partir de 1787 .

5 Ver Sessão de 17 de setembro de 1823, p. 158.

6 Ver, por exemplo: "Federação não se opõe à monarquia constitucional, como há exemplos, tanto na história antiga, como na moderna, e mesmo na Europa" (Assembleia Constituinte, 17 de setembro de 1823, pp. 152-153).

7 Sobre a ideia de casa como uma chave de leitura para a compreensão do pensamento imperial, ver Rohloff Mattos (1994).

8 Os federalistas não desconheciam as diferenças nas distintas trajetórias de Brasil e Estados Unidos. Um exemplo nesse sentido é a fala de Carvalho Melo, Sessão de 21 de outubro de 1823, p. 155.

9 A bibliografia sobre o debate usualmente não se detém no Código do Processo efetuando um salto histórico entre a Constituinte de 1823 e o Ato Adicional (1834). Os autores comentam os aspectos formais do Código do Processo, sem analisar os valores mobilizados no debate.

10 A lei que regia o cargo de juiz de paz permitia aos cidadãos ativos situados nos municípios a eleição direta do Juiz de Paz. O promotor e o juiz municipal eram escolhidos dentre os cidadãos locais pela câmara dos vereadores, enquanto o júri era sorteado dentre os cidadãos da localidade.

11 Sobre a ideia de interesse bem compreendido, ver Tocqueville (1977, livro II, parte II, cap. IX). 
12 O Astro de Minas, ano de 1832, e Aurora Fluminense, anos de 1832-1833.

13 Aurora Fluminense, 3/9/1832.

14 Aurora Fluminense, 3/9/1832 e 15/2/1833.

15 O Astro de Minas, 28/6/1832.

16 Ver, por exemplo, o jornal O Brasil, 20/11/1841.

17 Sessão de 17 de setembro de 1823, p. 158.

18 O Ato Adicional transferia as principais atribuiçōes da justiça para o controle do Legislativo provincial, que compartilhava o controle sobre funcionários da justiça com o poder central e possuía poder sobre os cargos judiciários na esfera municipal. O debate acerca do Ato Adicional tem início em 6 de maio de 1831, sua aprovação ocorre em agosto de 1834.

19 Anais da Câmara dos Deputados, sessão de 17 de maio de 1831, p. 48.

20 Idem, p. 47.

21 Idem, p. 48.

22 Ver, por exemplo, Evaristo da Veiga, Sessão da Câmara dos Deputados de 26 de junho de 1834, p. 182; Paula Araújo, Sessão da Câmara dos Deputados de 25 de junho de 1834, p. 173; ou Bernardo Pereira de Vasconcelos, Sessão da Câmara dos Deputados de 1 de julho de 1834, p. 10.

23 Nesse sentido, discordamos da crítica bem elaborada por Ferreira (2009). Segundo a autora, teríamos associado o argumento federalista a uma incapacidade em formular o interesse nacional.

24 Sobre a força das províncias no pacto político imperial ao longo do século XIX, ver Dolhnikoff (2005).

25 Ver, por exemplo, o discurso de Feijó na sessão do Senado em 26 de julho de 1839, p. 371.

26 Álvares Machado designa a centralização como cadeia de ferro que comprime os interesses das províncias. Ver sessão de 3 de junho de 1839.

27 Sessão da Câmara dos Deputados de 12 de junho de 1839 , p. 383. Segundo os centralizadores, em algumas províncias, o Legislativo provincial extinguiu cargos previstos no Código do Processo, transferindo suas atribuições para outros cargos, ou simplesmente suprimindo-os, mas sem definir quais cargos herdariam suas tarefas. No debate da época, eram chamadas de Leis provinciais absurdas.

28 A bibliografia sobre o tema ignora a contraposição entre interesse meramente provincial e vontade nacional, presente num dos mais importantes relatórios de ministro da justiça. Tal silêncio é compreensível, na medida em que seu material de análise passa ao largo do debate ocorrido em torno do Ato Adicional nos anos de 1830 .

29 Esse termo, segundo Moraes (1844), significava "a faculdade que alguém tem de querer". O significado de vontade denotava uma deliberação tomada pelo agente no sentido de realizar um ato intencionalmente buscado.

$30 \mathrm{Tal}$ chave interpretativa pode ser encontrada em Mello (2001, p. 16).

31 Ver, por exemplo, Souza, Relatório de Presidente de Província do Ano de 1839, p. 4. Sobre uma análise detalhada dos debates em torno destes cargos, ver Coser (2008, cap. 5).

32 Ver sessão da Câmara dos Deputados de 3 de novembro de 1841, p. 815.

33 Ver Sessão do Senado de 6 de julho de 1840, p. 14

34 Esse aspecto é mencionado na sessão de 5 de agosto de 1846, na Câmara dos Deputados, nas palavras do Cônego Marinho: "E por que oferece o subdelegado mais garantias do que o juiz de paz? Porque o subdelegado é da nomeação do governo?".

35 A Cabanagem e a Farroupilha.

36 Ver Relatório de 1841, pp. 7-10.

37 Idem, ibidem.

38 Sobre o par conceitual civilização/sertão no pensamento político imperial, ver Coser (2008, cap.4).

39 Ver também Nabuco (1997, vol. I, pp. 101-105). O autor, abordando os conflitos da política regional entre partido da ordem e praieiros, analisa a reação dos senhores de engenho contra a Reforma do Código.

40 Ver Relatório de Ministro da Justiça, 1843, p. 26.

41 Idem, ibidem.

42 Ver Sessão de 17 de junho de 1839.

43 Sobre a importância de análise do argumento a partir de onde é proferido, ver Wolin (1976, pp. 26-27).

44 Uma releitura da ideia de iberismo pode ser encontrada em Werneck Vianna e Carvalho (2000).

45 Sobre as diferenças entre o liberalismo anglo-saxão e o francês no século XIX, ver Sidentop (1979). Sobre o liberalismo francês, ver Rosanvallon (1985).

46 Ver, principalmente, os Anais dos debates parlamentares do Senado no ano de 1850.

47 O Judiciário cuida do interesse privado e do direito dos associados. Ver Ribas (1866, p. 78).

48 "O direito [...] está inerente a alguém por virtude da lei. Tal é o que está inerente à qualidade de proprietário ou cidadão" (Uruguai, 1997 [1862], cap. XV, p. 63). 
Segundo o Visconde do Uruguai, "pertencem a todos independentemente da sua capacidade" (Idem, nota 8). Ver Pimenta Bueno (1978 [1858], pp. 381-382).

49 Ver também Uruguai (1997 [1862], p. 73) e Rego (1860, p. 8).

50 Sobre o uso de Tocqueville pelo Visconde do Uruguai e por Tavares Bastos, ver Ferreira (1999).

51 Sobre a incapacidade dos interesses privados em compreender a necessidade da abolição do tráfico, ver Anais do Senado, 1850, vol. I, p. 319, e Uruguai (1997 [1862], p. 72).

\section{BIBLIOGRAFIA}

\section{Fontes Primárias}

Anais da Câmara dos deputados dos anos de: 1823, 1827, 1831, 1832, 1833, 1834.

Anais do Senado dos anos de 1840 e 1850.

Relatórios de Ministro da Justiça dos anos de 1834, 1836, $1841,1843$.

JORNAIS: O Astro de Minas (1832), Aurora Fluminense (1834), O Brasil, (1841).

\section{Livros}

BASTOS, Aureliano Candido Tavares. (1937 [1870]. A Província. 2 ed. São Paulo, Editora Nacional.

BRANDÃO, Gildo Marçal. (2007), Linhagens do pensamento político brasileiro. São Paulo, Aderaldo \& Rothschild.

BUENO, José Antônio Pimenta. (1978 [1858]), Direito público brasileiro e análise da Constituição do Império. Brasília, Senado Federal.

CARVALHO, José Murilo de. (1980), A construção da ordem. Brasília, Editora da UnB.

. (1993), "Federalismo y centralización en el Imperio brasileño: historia y argumento", in Marcelo Carmagnani (org.), Federalismos latinoamericanos: Mexico/Brasil/Argentina. México, Fondo de Cultura Económica.

(2002), "Entre a autoridade e a liberdade", in Visconde do Uruguai (org. e introdução de José Murilo de Carvalho). São Paulo, Editora 34.
CARVALHO, Maria Alice Rezende de. (1988), O quinto século: André Rebouças e a construção do Brasil. Rio de Janeiro: Revan/Iuperj/Ucan.

COSER, Ivo. (2008), Visconde do Uruguai: centralização e federalismo no Brasil. (1823-1866). Belo Horizonte/Rio de Janeiro, Editora da UFMG/Iuperj, 2008.

DOLHNIKOFF, Miriam. (2005), O pacto imperial: origens do federalismo no Brasil do século XIX. São Paulo, Globo.

FAORO, Raymundo. (1994), Existe um pensamento politico brasileiro? São Paulo, Ática.

FERNANDES, Florestan. (1975), A revolução burguesa no Brasil. Parte 1: As origens da revolução burguesa. Rio de Janeiro, Zahar, 1975.

FERREIRA, Gabriela Nunes. (1999), Centralização e descentralização no Império: o debate entre Tavares Bastos e visconde do Uruguai. São Paulo, Departamento de Ciência Política da Universidade de São Paulo/Editora 34.

. (2009), "Um debate em aberto: centralizadores e federalistas na construção do Estado nação do Brasil”. Revista Brasileira de Ciências Sociais, 24 (71): 176-179.

JASMIN, Marcelo. (2000), "Interesse bem compreendido e virtude em $A$ Democracia na América", in Newton Bignotto (org.), Pensar a República, Belo Horizonte, Editora da UFMG.

KOSELLECK, Reinhart. (2002), The practice of conceptual history. Stanford, Stanford University Press.

MATTOS, Ilmar Rohloff. (1994), O tempo de Saquarema: a formação do Estado imperial. 3 ed. Rio de Janeiro, Acess.

MORSE, Richard. (1988), O Espelho de Próspero. São Paulo, Companhia das Letras.

MELLO, Evaldo Cabral de. (2004), A outra Independência: o federalismo pernambucano de 1817 a 1824. São Paulo, Editora 34.

NABUCO, Joaquim. (1997), Um estadista do Império. 5 ed. Rio de Janeiro, Topbooks.

REGO, Walquiria. (1989), Um liberalismo tardio: Tavares Bastos, reforma e federação. São Paulo, tese de doutorado, Departamento de Ciência Política, USP (mimeo.).

REGO, Vicente Pereira. (1860), Elementos de direito administrativo brasileiro. 2 ed. Recife. Dispo- 
nível em <www.bdjur.stj.gov.br>.

RIBAS, Joaquim. (1866), Direito administrativo brasileiro. Rio de Janeiro, Pinto Livreiros. Disponível em <www.bdjur.stj.gov.br $>$.

ROSANVALLON, Pierre. (1985), Le moment Guizot. Paris, Gallimard.

SANTOS, Wanderley Guilherme. (1978), Ordem burguesa e liberalismo político. São Paulo, Duas Cidades.

SIDENTOP, Larry. (1979), “Two liberal traditions", in Alan Ryan (ed.), The idea of freedom: essays in honour of Isaih Berlin. Oxford, Oxford University Press.

TOCQUEVILLE, Aleixs de. (1977), A democracia na América. Belo Horizonte, Itatiaia.

WOLIN, Sheldon. (1976), "Filosofía política y filosofía", in , Política y perspectiva. Buenos Aires, Amorrortu Editores.

Uruguai, Visconde do. (Paulino José Soares de Souza). (1858), Bases para uma melhor organização das administraçôes provinciais. Rio de Janeiro, Typografia Nacional. . (1997 [1862]), Ensaio sobre o direito administrativo. Brasília, Ministério da Justiça. . (1865). Estudos práticos sobre a administração das províncias no Brasil. Rio de Janeiro, Imprensa Oficial.

VIANNA, Luis Werneck. (1997), A revolução passiva: iberismo e americanismo no Brasil. Rio de Janeiro, Revan.

VIANNA, Luis Werneck \& Carvalho, Maria Alice Rezende de. (2000), "República e civilização brasileira”, in Newton Bignotto (org.), Pensar a República, Belo Horizonte, Editora da UFMG. 


\section{O DEBATE ENTRE CENTRALIZADORES E FEDERALISTAS NO SÉCULO XIX: A TRAMA DOS CONCEITOS}

\section{Ivo Coser}

Palavras-chave: Pensamento político; Centralização; Federalismo; Autoritarismo; Americanismo; Iberismo.

Este artigo tem como objetivo entender as principais mudanças no conteúdo dos conceitos de centralização e federalismo ao longo do século XIX, articulando-as com as linhas de interpretação do pensamento político brasileiro. No pensamento centralizador esteve presente a precedência do interesse público ante os interesses particulares. Tal subordinação não nasce da compreensão de um atraso existente na sociedade, o qual caberia ao Estado corrigir por meio de instrumentos autoritários, mas de uma precedência necessária decorrente da legitimidade que esse órgão possui perante a sociedade. $\mathrm{O}$ pensamento federalista foi marcado pela ideia do interesse individual articulado à busca da liberdade do cidadão e da autonomia das províncias. Buscamos interpretá-lo por meio do conceito de americanismo e das alteraçôes no contexto histórico.

\section{THE DEBATE BETWEEN CENTRALIZERS AND FEDERALISTS IN THE $19^{\mathrm{TH}}$ CENTURY: THE PLOT OF CONCEPTS}

\section{Ivo Coser}

Keywords: Political thought; Centralization; Federalism; Authoritarianism Americanism; Iberism.

This article aims at understanding the main changes in the content of concepts of centralization and federalism along the $19^{\text {th }}$ century, combing them with the lines of interpretation of the Brazilian political thought. In the centralizing thought there was the precedence of public interest in confrontation with private interests. Such subordination does not arise from realizing an existing delay in the society which would be up to the state to correct by duty means of authoritarian instruments, but rather from the legitimacy that this body has had towards society. The federalist thought was marked by the idea of individual interest established by the search of the citizen's freedom and the autonomy of provinces. We have tried to interpret it by means of historical context changes.

\section{LE DÉBAT ENTRE CENTRALI- SATEURS ET FÉDÉRALISTES AU XIX $^{\text {e }}$ SIËCLE: LA TRAME DES CONCEPTS}

\section{Ivo Coser}

Mots-clés: Pensée politique; Centralisation; Fédéralisme; Autoritarisme; Américanisme; Ibérisme.

Cet article a pour objectif de comprendre les principaux changements dans le contenu des concepts de centralisation et de fédéralisme au cours du XIX ${ }^{\mathrm{e}}$ siècle, en les reliant aux lignes d'interprétation de la pensée politique brésilienne. La primauté de l'intérêt public face aux intérêts privés a été présente dans la pensée centralisatrice. Une telle subordination ne naît pas de la compréhension d'un retard existant dans la société - et qui devrait être corrigé par l'État par l'emploi d'instruments autoritaires - mais d'une précédence nécessaire découlant de la légitimité que l'État possède auprès de la société. La pensée fédéraliste a été marquée par l'idée de l'intérêt individuel articulé à la recherche de la liberté du citoyen et de l'autonomie des provinces. Nous cherchons à l'interpréter par le concept de l'américanisme et des changements dans un contexte historique. 